\title{
Proposta de uma ontologia como modelo de referência no domínio da Memória Organizacional Histórica
}

Janete Saldanha Bach Estevão

Graduada em Biblioteconomia pela Universidade Federal do Paraná.Mestre em Tecnologia e Sociedade pela Universidade Tecnológica Federal do Paraná. Consultora em organização e gestão de coleções especiais das áreas de Marketing e Memória Organizacional

Faimara do Rocio Strauhs

Doutorado em Engenharia de Produção pela Universidade Federal de Santa Catarina PósDoutorado no Instituto de Engenharia de Sistemas e Computadores do Porto (INESCPorto), Portugal. Professor classe D-IV da Universidade Tecnológica Federal do Paraná

A Memória Organizacional Histórica é constituída dos principais documentos que registram a trajetória de uma Instituição. As ontologias visam a dar sentido ao conteúdo destes repositórios, valendo-se da relação semântica dos termos que representam esse domínio. O presente estudo estabelece bases para a proposição de uma ontologia que sirva como modelo de referência no domínio da Memória Organizacional Histórica, a fim de promover precisão nas respostas dos sistemas de busca e recuperação da informação. O universo desta pesquisa exploratória é representado pelas empresas participantes do fórum Permanente de Gestão do Conhecimento, Comunicação e Memória da Associação Brasileira de Comunicação Empresarial (ABERJE), que já possuem iniciativas em Memória Organizacional Histórica (MOH). Identifica-se, entre outros aspectos, se estas empresas utilizam alguma forma padronizada de representação da informação, como vocabulários controlados, taxonomias ou tesauros. A coleta de dados foi feita com entrevistas em campo, seguida da análise de conteúdo e descrição dos resultados obtidos. Pretende-se que essa ontologia sirva como um modelo de referência para projetos de Memória Organizacional Histórica, podendo ser extensível pelos especialistas do domínio, a partir dos conceitos declarados e inter-relacionados nesta proposta, a tipologia 
documental, a coleções, a assuntos cobertos pelo acervo, público-alvo e canal de disseminação das informações.

\section{Palavras-chave: Memória organizacional histórica; Gestão do conhecimento organizacional; Ontologias; Representação da Informação.}

\section{Proposal of an ontology as a reference model in the field of Historical Organizational Memory}

The Historical Organizational Memory consists of the main documents that register the trajectory of an institution. The ontologies aim to make sense of the content of these repositories, using the semantic relationship of the terms that can represent the area. This work establishes the basis for proposing an ontology that serves as a reference model in the Historical Memory Organization field, promoting accurate responses from search engines and information retrieval. The universe of this research is represented by companies participating in the Permanent Forum on Knowledge Management, Communication and Memory of the Brazilian Association of Business Communication (ABERJE), which already have initiatives in Historical Organizational Memory (HOM). It identifies, among other things, whether companies use a standardized instrument of information representation, such as controlled vocabularies, taxonomies and thesauri. We used the exploratory research, interviews with data collection, followed by content analysis and description of the results. It is intended that this ontology will serve as a reference model for Historical Organizational Memory projects, which can be extended by domain experts from the declared and interrelated concepts in this proposal: types of documents, collections, subjects covered by the items, the target audience and information dissemination channels.

Keywords: Organizational historical memory; Organizational knowledge management; Ontologies; Representation of information.

Recebido em 28.05.2012 Aceito em 19.05.2013 


\section{Introdução}

O conceito Memória Organizacional (MO) é tratado, neste artigo, sob a perspectiva da trajetória histórica das organizações, por isso convencionou-se acrescentar o termo qualificador Histórica, construindose a expressão Memória Organizacional Histórica (MOH). Esta diferenciação se faz necessária porque é utilizado na literatura o termo Memória Organizacional para embasar projetos de gestão, de armazenamento e de recuperação de informação organizacional em diversas áreas específicas das empresas, como, por exemplo: Contabilidade, Jurídica, Técnica, entre outras (ESTEVÃO; STRAUHS, 2011).

A memória organizacional com enfoque de resgate histórico tem sido utilizada como ferramenta de suporte à gestão para instituições de diversos portes e diferentes setores da economia do país. Muitas são as possibilidades de produtos desenvolvidos a partir de ações de Memória Organizacional Histórica, como publicações institucionais, exposições e museus, Centros de Documentação e Memória, entre outros. Esses produtos têm diversas possibilidades de aplicação, a partir das suas características - reforçar a comunicação interna e externa, promover o marketing institucional ou de produtos e serviços, apoio ao endomarketing e gestão estratégica das organizações.

Contudo, o fato de uma iniciativa de $\mathrm{MOH}$ existir em uma determinada instituição não significa que seja utilizada de forma otimizada e estratégica (BROOKING, 1999, p. 155). Pode-se citar como exemplo de uso estratégico de informações históricas aquelas contidas nos documentos publicitários, veiculadas em revistas e jornais, que podem servir de embasamento a peças jurídicas, ou os dados e as informações referentes ao desenvolvimento de produtos e serviços, desde os primeiros protótipos até o primeiro lote produzido, transformados em briefings e business cases.

Esses documentos registram importantes informações sobre a trajetória, a cultura, os processos e a memória da Organização. Entretanto, de acordo com os resultados da pesquisa apresentados neste artigo, os documentos e conteúdos históricos institucionais, quando armazenados em repositórios, normalmente não seguem uma padronização de representação da informação, que agregue efetivo valor a esta, ou favoreça seu uso e recuperação otimizados.

Diversos autores têm atestado a aplicação de ontologias na melhoria de processos de recuperação da informação (BERNERS-LEE; HENDLER; LASSILA, 2001; JASPER; USCHOLD, 1999; GUARINO, 1997; MCGUINNESS, 1998; SOWA, 2000; W3C, 2011a; WELTY, 1998). Sendo a ontologia uma forma de melhorar a performance da recuperação da informação, a falta desta padronização e do estabelecimento de relações semânticas dos termos a serem utilizados para representar a informação, concomitante com a falta de explicitação do relacionamento entre esses termos, pode malograr as respostas de buscas nos repositórios organizacionais, o que implicaria em subutilização da coleção institucional. 
Todavia, os estudos sobre as ontologias relacionadas com a Memória Organizacional Histórica na Ciência da Informação ainda são incipientes. Um levantamento bibliográfico retornou apenas um artigo para o período desde 1977 até Março de 2006 (NASCIMENTO et al., 2007, p. 35). Esta mesma pesquisa foi replicada em março de 2012, em bases como a Library \& Information Science Abstracts (LISA), Documents in Information Science (DoIS), E-prints in Library and Information Science (E-LIS) Information Science \& Technology Abstracts (ISTA), além do Google acadêmico, tendo sido recuperados apenas três artigos publicados a partir de 2006 até 2012.

Neste cenário, este artigo baseia-se na premissa de que uma ontologia pode contribuir para a recuperação da informação, pois promove o alinhamento dos conceitos e suas relações em um dado domínio, identifica os documentos/conteúdos do repositório pertinentes ao domínio, dinamiza e maximiza os resultados da recuperação da informação, apoiando as organizações no resgate de informações e gestão do conhecimento registrado. Assim, propõe-se uma ontologia que sirva como modelo de referência no domínio da Memória Organizacional Histórica, elaborando o desenho conceitual de suas relações semânticas que, de seu turno, embase o desenvolvimento de ferramentas de busca e a recuperação da informação, retornando respostas mais precisas e efetivas.

Avalia-se que o entendimento semântico no domínio de $\mathrm{MOH}$ pode ser útil às organizações, na compreensão da rede de significados e suas inter-relações, ou, ainda, permite "possibilitar a definição de um conjunto de conceitos, relações e propriedades, de forma que um sistema possa obter o contexto e o significado dos termos que manipula, e, assim, realizar inferências" (ALMEIDA, 2006, p. 112).

Neste artigo, apresenta-se, na seção 2, uma breve revisão da literatura sobre a Memória Organizacional Histórica, seguida da revisão de literatura em Ontologias e recuperação da informação, na seção 3. Na seção 4, apresenta-se a metodologia utilizada para a pesquisa. Na seção 5, são demonstrados os resultados obtidos e, na seção 6, as considerações finais.

\section{Conceitos e decorrências da memória organizacional}

A Memória Organizacional Histórica é um conceito que tem se consolidado no país a partir dos anos 1990 (TONINI; GAGETE, 2004a, p. 118), apesar dos primeiros trabalhos caracterizados como $\mathrm{MOH}$ serem da década de 1960. Entretanto, muitas empresas que trabalham a $\mathrm{MOH}$ ainda restringem 0 uso destas ações ao aspecto celebrativo, como publicações de livros, vídeos e Cds, hot sites e linhas do tempo, por ocasião de aniversários institucionais. Tonini e Gagete (2004a, p. 120) alertam que muitos dos projetos de $\mathrm{MOH}$ ainda têm por objetivo único o registro da história ou das histórias e "causos" curiosos que marcaram a trajetória da empresa, servindo apenas como peça de comunicação 
institucional e de marketing corporativo, o que subutiliza o potencial destes projetos.

Tonini e Gagete (2004a, p. 120) defendem que esses projetos sirvam como "ferramentas de gestão estratégica, quer no que se refere ao autoconhecimento necessário às tomadas de decisão do presente planejamento do futuro, quer na construção de políticas de relacionamento com seus stakeholders ${ }^{1 " .}$.

Para Damante (2004), uma das preocupações das companhias que tem iniciativas de MO é a responsabilidade histórica de seu legado para si mesma e para a sociedade, na medida em que a sua evolução se mescla e se confunde com a evolução da sua própria área de atuação ou com o seu próprio país. Essa trajetória se explicita pela narrativa institucional das organizações. Assim como a história pessoal é a organização do que seletivamente o indivíduo guarda na memória, a história de um grupo é a organização do que foi seletivamente demarcado como significativo em sua trajetória e que permanece como fundamento histórico de sua cultura implícita.

É elemento essencial, nesse sentido, a Memória Coletiva, que envolve a memória pessoal, a memória do processo, das relações, dos espaços, dos objetos, memória da marca, entre outros. Portanto, a narrativa institucional é o conjunto de fatos, de pessoas e de processos selecionados pelo grupo ao longo de seu processo histórico e contém sempre uma perspectiva sobre os processos selecionados e traduz a cultura presente da instituição (WORCMAN, 2004).

Infere-se que as iniciativas de $\mathrm{MOH}$, desta perspectiva, servirão, de fato, como canais disseminadores do conhecimento organizacional, principalmente aquele gerado pelos processos de Marketing, Comunicação Corporativa, Recursos Humanos, Responsabilidade Social e Ambiental, Planejamento Empresarial e processos produtivos, que podem ser de uso estratégico para a Empresa e não apenas guardiãs de registros internos, desconectados de seus contextos.

\subsection{Memória Organizacional Histórica e a Gestão do Conhecimento}

Nas organizações, a memória é corporativa e tem origem nas memórias individuais, além de ser um espaço para atuação e investigação multidisciplinar. Os conhecimentos registrados pelos indivíduos interagem com o conhecimento próprio dos papéis e responsabilidades que esses assumem na organização (REMOR; RADOS; REMOR, 2009, p. 88).

Para Walsh e Ungson (1991), a memória organizacional está diretamente relacionada com as informações contidas na trajetória de uma organização. Essas informações, frutos de decisões já tomadas, dos processos cognitivos dos indivíduos e de interpretações em conjunto, são passiveis de recuperação e viabilizam as decisões presentes (WALSH;

${ }^{1}$ Stakeholders - São as partes interessadas: indivíduos ou entidades que assumam algum tipo de risco, direto ou indireto, em face da sociedade. São elas, além dos acionistas, os empregados, clientes, fornecedores, credores, governos, entre outros. (IBGC, [s.d.]). 
UNGSON, 1991). A Memória Organizacional, nessa perspectiva, é uma construção conjunta, em nível individual e organizacional. Para tanto, Walsh e Ungson (1991) destacam os processos de aquisição, retenção e recuperação da informação dentro do ambiente organizacional. Tais processos, sob uma ótica sistêmica, remetem ao que se convenciona hoje chamar de Gestão do Conhecimento (GC).

A Memória Organizacional Histórica tem por objetivo recolher, preservar e disseminar de uma forma sistemática os recursos de conhecimento da trajetória de uma organização, sendo uma ação de GC. As formas de trabalhar a memória organizacional histórica vão do resgate e restauração de documentos fundadores e arquivos fotográficos até a estruturação de Centros de Memória e Referência, nos quais a memória é trabalhada como conhecimento, diz Nassar (2009). Nesse contexto, inserem-se o conhecimento explícito e o tácito, duas dimensões amplamente discutidas e conceituadas na obra de Nonaka e Takeuchi (1997, p. 113). Os autores, baseados nessa diferenciação do conhecimento tácito e explícito inicialmente proposta por Michel Polany em 1966, definem o primeiro como sendo "pessoal, dependente do contexto, e, portanto, difícil de ser formalizado e comunicado". O conhecimento explícito, porém, pode ser transmitido em linguagem formal e sistemática, é mais objetivo e está ligado à razão e à teoria. Porém, representa uma pequena parte do conhecimento total existente (NONAKA; TAKEUCHI, 1995, p. 59-60).

Tendo como base o entendimento que conhecimento explícito é constituído de dados que foram, de alguma maneira, codificados, estes podem ser processados por sistemas de tecnologia de informação e comunicação, viabilizando sua armazenagem e recuperação em banco de dados (SPILLER, 2005, p. 29). A partir do exposto acima, pode-se entender que uma ação de $\mathrm{MOH}$ que pretenda servir como uma ferramenta de Gestão do Conhecimento Organizacional precisa contemplar maneiras de extrair o conhecimento tácito, para que este se torne explícito, possa ser codificado, registrado, preservado e acessível mediante ferramentas computacionais, para que, ao ser acessado e processado mentalmente por outros indivíduos, se torne novamente em conhecimento tácito (CHOO, 2003, p. 28).

Por ter uma visibilidade externa mais acentuada, principalmente se o acesso é estendido para fora das fronteiras da empresa, a $\mathrm{MOH}$ tem se tornado uma das "garotas-propaganda" da Gestão do Conhecimento. Porém, produtos de $\mathrm{MOH}$ focados em resgate históricos como "show rooms e livros históricos, publicações, exposições e eventos" (MUSEU DA PESSOA, 2005), além de seu acervo documental institucional, como "objetos, embalagens, fotos, campanhas, documentos e registros com valor de guarda permanente" (DAMANTE, 2004, p. 30), precisam, efetivamente, servir de fomento à Gestão do Conhecimento. Assim, é preciso sistematizar as informações codificadas, organizar o conhecimento registrado que a empresa tem de si mesma, de forma linear. Mas, também, resgatar oralmente dos seus colaboradores uma memória que 
não está formalmente registrada em manuais ou documentos. Esta seria, sem dúvida, uma forma de extração do conhecimento tácito.

Destaca-se, com corroboração de Tonini e Gagete (2004b), como principal produto de $\mathrm{MOH}$ o Centro de Documentação e Memória (CDM), por este ter um processo contínuo de preservação histórica da Instituição. Os CDMs têm similaridades em relação às funções de custódia de documentos, como encontradas nos museus, arquivos e nas bibliotecas. Entretanto, têm particularidades em relação as suas funções específicas, em como são constituídos os seus acervos, às características dos documentos, ao processamento técnico, aos seus produtos e serviços de informação e ao perfil de seu público.

\subsection{Os centros de documentação e memória (CDMs)}

Por ser o mais completo produto de Memória Organizacional Histórica, o CDM dá suporte a todos os demais produtos e serviços. Mais do que espaços destinados à guarda de registros históricos ou de celebração do passado, são setores prestadores de serviços de informação, voltados ao atendimento das demandas dos diversos públicos da empresa. São, também, responsáveis pelo resgate contínuo e tratamento técnico sistemático de diferentes tipos de acervo e pela disseminação de informações pertinentes à evolução do negócio.

A diversidade do acervo dos CDMs vai de publicações tradicionais, como acervos bibliográficos, até coleções especiais da organização e banco de depoimentos de colaboradores. Logo, o acervo organizado tornase um importante aliado na Gestão do Conhecimento. Sua preservação e disponibilidade promovem o entendimento de relações históricas e dos contextos organizacional, socioeconômico e político, propiciando insumos para decisões estratégicas. O entendimento de quais elementos essenciais a $\mathrm{MOH}$ é constituída, quais são seus requisitos estruturais, ajuda a diagnosticar e a viabilizar formas de melhor exteriorização e compartilhamento do conhecimento dentro da organização.

A seguir, apresenta-se a importância das ontologias como estruturas de conceituação e relacionamentos entre termos de um dado domínio, que visam, ao promover a semântica desse domínio, à recuperação mais relevante, já que utiliza as informações contextualizadas para essa busca. As ontologias tornam-se a estrutura conceitual utilizada para representar o conhecimento explícito sobre $\mathrm{MOH}$.

\section{A representação da informação e as ontologias}

A disponibilização dos conteúdos informacionais pelos métodos e técnicas da biblioteconomia é realizada a partir de representações sobre o conhecimento contido nas obras de um acervo construído, independentemente de ser o seu suporte físico ou virtual. Essas representações são tanto descritivas quanto temáticas. Elas visam a descrever os recursos de um documento com a finalidade de facilitar e tornar mais efetiva a busca e recuperação da informação. Quando a 
biblioteca do Congresso Americano começou a utilizar computadores, nos anos 1960, foi criado um padrão de catalogação que deu origem ao formato MARC 21 (MAchine-Readable Cataloging record) , "um sistema de utilização de números curtos, letras e símbolos dentro do registro para catalogação, que identifica diferentes tipos de informação" (LIBRARY OF CONGRESS, 2009).

Esses esforços foram feitos justamente para que esses dados pudessem ser lidos e operados por máquinas, viabilizando a troca automática de metadados de uma determinada publicação entre aplicativos de diferentes bibliotecas. Percebe-se que, na década de 1960, com o surgimento do padrão MARC, já se aplicava na biblioteconomia o conceito de interoperabilidade de sistemas, ou seja, a "troca de informações entre sistemas" (LIBRARY OF CONGRESS, 2009).

Tem destaque, também, a iniciativa da Online Computer Library Center $(\mathrm{OCLC})^{2}$, ao criar o WorldCat ${ }^{3}$, que é uma rede global de prestação de serviços às bibliotecas. Foi construído cooperativamente a partir do desenvolvimento de bases de dados de metadados para registros bibliográficos e institucionais, para a troca desses registros entre os participantes da rede. Atualmente, soma quase 1 bilhão e setecentos milhões a quantidade de registros trocados (ONLINE..., 2011).

A outra forma de descrição de um documento, apontada por Cesarino e Pinto (1980), a intelectual ou subjetiva, refere-se à identificação de seu conteúdo informacional. Cesarino e Pinto (1980) descrevem o processo para estabelecer o assunto de um documento em três etapas. Inicialmente, a necessidade de compreensão do documento como um todo, o que não implica leitura integral do texto, mas a seleção e leitura de partes importantes como título e subtítulos, introdução, ilustrações, tabelas, diagramas, conclusões, entre outros.

$\mathrm{Na}$ segunda etapa, selecionam-se os conceitos que melhor expressam o assunto do documento. A terceira etapa consiste em refinar a seleção da segunda etapa, escolhendo apenas termos que realmente são válidos para indexação. Estes termos são descritores validados por algum instrumento padronizador. Estes instrumentos, denominados de tesauros, listas de cabeçalhos de assunto e taxonomias, podem ser adquiridos, customizados ou construídos a partir de metodologias já consagradas na literatura (DAHLBERG, 1978; INSTITUTO BRASILEIRO DE INFORMAÇÃO EM CIÊNCIA E TECNOLOGIA - IBCT, 1984; GOMES, 1990).

Todo este processo de indexação é realizado com base no conhecimento implícito, a partir de uma formação específica para capacitação no entendimento e uso desses instrumentos, na análise dos assuntos e na escolha dos descritores que melhor representem esses assuntos, considerando questões de polissemia e sinonímia.

Nesse sentido, as ontologias surgem como uma proposta que permite automatizar parcialmente esse processo, sem perder a riqueza do

\footnotetext{
${ }^{2}$ Centro de Computação em linha para Biblioteca.

${ }^{3}$ Catálogo mundial de cooperação de registros bibliográficos (ONLINE..., 2011).
} 
conhecimento tácito contido nas pessoas, mas explicitando-o de uma forma estruturada, padronizada, legível ou interpretável por máquina, que permite a interoperabilidade (troca) de informações por sistemas, agrupando documentos por área de interesse e passíveis de compartilhamento e reuso (USCHOLD, 1996).

Os estudos em ontologias aplicadas à recuperação da informação iniciaram na área da Inteligência Artificial (IA), ramo da Ciência da Computação (CC), na década de 1990. A conceituação de Guarino (1998, p.2) considera ontologia em IA como um artefato de engenharia:

Em seu uso mais relevante em IA, uma ontologia refere-se a um artefato de engenharia, constituído por um vocabulário específico usado para descrever certa realidade, mais um conjunto de pressupostos explícitos sobre o sentido intencional das palavras do vocabulário. Esse conjunto de premissas geralmente está expresso de acordo a teoria de lógica de primeira ordem, onde aparecem palavras do vocabulário como predicado unário ou binário, respectivamente chamados conceitos e relações. No caso mais simples, uma ontologia descreve uma hierarquia de conceitos relacionados por relações subentendidas; em casos mais sofisticados, axiomas adequados são adicionados a fim de expressar outras relações entre conceitos e para restringir sua interpretação pretendida (GUARINO, 1998, p. 2, tradução nossa).

Um marco nas pesquisas de como melhorar as respostas dos sistemas de buscas na internet foi a criação da World Wide Web Consortium (W3C) por Tim Berners-Lee e outros pesquisadores, em 1994 (W3C, 2011a). A W3C é um consórcio internacional que projeta uma web (rede) em que a recuperação da informação seja feita de forma mais assertiva e contextualizada, com um processamento inteligente, a qual denominou-se de Web Semântica (W3C, 2011b). A W3C faz uso de princípios como interoperabilidade, evolução e descentralização para identificar novas tecnologias e padronização para a rede.

O primeiro passo para se atribuir semântica à rede web, visando melhorar a busca e recuperação de informação, é a construção das ontologias (BERNERS-LEE; HENDLER; LASSILA, 2001). As ontologias vêm sendo utilizadas pela W3C como instrumentos de padronização terminológica para viabilização desses resultados. Elas são compostas de uma taxonomia e de regras de inferência. Inferências são as deduções que a máquina faz automaticamente a partir de dados fornecidos.

Para Sales, Campos e Gomes (2008, p. 63), em função da estrutura de uma ontologia ser formada por termos, definições e relações, ela se caracteriza como uma linguagem documentária, porém, com uma vantagem: possui funcionalidades que permitem o processamento automatizado do raciocínio pela máquina, valendo-se de regras e 
inferências. Entretanto, em virtude das diferentes aplicações e usos da ontologia, ainda não é consenso na área seu status de linguagem documentária. Em relação às inferências, Dziekaniak (2010, p. 53) afirma que "esta propriedade faz das ontologias a melhor solução atualmente para sistemas de recuperação da informação, uma vez que podem ser processadas automaticamente ao fazerem uso de relacionamentos lógicos e axiomáticos". Ainda para Kobashi (2007), "as ontologias pretendem ir além dos tesauros documentários. Essas abordagens ampliam as possibilidades de organizar e ter acesso à informação em sistemas", embora este não seja o enfoque definitivo para a Ciência da Informação.

As similaridades das ontologias com as linguagens documentárias, na percepção de Campos (2004), Sales (2006), Boccato, Ramalho e Fujita (2008), Ramalho (2010), é suficiente para considerá-las como instrumento de representação e de recuperação da informação. Sendo assim, as ontologias também podem ser abordadas sob a ótica da Biblioteconomia e Ciência da Informação, ocupadas também com o desenvolvimento de sistemas de recuperação da informação.

A estrutura das relações construídas nos vocabulários controlados e tesauros é um "modelo diático que revela apenas as categorias as quais os conceitos pertencem" (SALES; CAMPOS; GOMES, 2008, p. 64). Nesse estudo, o modelo diático é descrito como evidenciação de pares de categoria, por exemplo: processo-resultado (SALES; CAMPOS; GOMES, 2008, p. 74).

Já nas ontologias, é utilizado o modelo triádico, ou seja, essas relações demandam uma explicitação, integrando uma proposição. É composto por três partes: categoria antecessora, relação formal e categoria sucessora, por exemplo: processo_gera um resultado. Destarte, as ontologias são capazes de melhor representar o conhecimento, pois envolvem a análise semântica, em que a máquina infere novas relações que não estão explicitamente descritas, mas estão implícitas nas relações e nos axiomas declarados.

São diversas as áreas do conhecimento em que se identifica a aplicação de ontologias como fator de melhora de respostas na recuperação da informação em sistemas informatizados. Neste artigo, a aplicação de ontologias insere-se nos estudos organizacionais e a seguir se apresentam os procedimentos utilizados na elaboração desta pesquisa.

\section{Procedimentos metodológicos da pesquisa}

A pesquisa foi realizada em 11 instituições que já aplicam iniciativas em $\mathrm{MOH}$ e que possuem CDMs, participantes do programa de fomento à memória das organizações, o Fórum Permanente de Gestão do Conhecimento, Comunicação e Memória, da Associação Brasileira de Comunicação Empresarial (ABERJE). O Fórum permite a troca de experiências entre os associados e convidados externos. Entre as atribuições do Fórum, está "disseminar informações sobre história e memória empresarial, promover GC, estimular e reconhecer práticas de 
excelência, reunindo profissionais com interesses e desafios comuns" (ASSOCIAÇÃO BRASILEIRA DE COMUNICAÇÃO EMPRESARIAL, 2008).

O objeto de estudo foi investigado a partir de uma pesquisa de campo, tendo sido aplicadas entrevistas na modalidade semiestruturadas, o que permite que os respondentes tenham o mesmo conjunto de perguntas padrão. Após a seleção de técnicas de análise das respostas, a interpretação das entrevistas foi baseada na análise de conteúdo de Bardin (1995), Esse processo se dá no "desmembramento do discurso em categorias, em que os critérios de escolha e de delimitação orientam-se pela dimensão da investigação dos temas relacionados ao objeto de pesquisa, identificados nos discursos dos sujeitos pesquisados" (BARDIN, 1995, p. 80-81). Baseia-se em um conjunto de técnicas de análise de comunicação, viabilizando, a partir de procedimentos sistemáticos e objetivos de descrição do conteúdo das mensagens, obter indicadores quantitativos ou não, que permitam a inferência de conhecimentos relativos às condições de produção e recepção das mensagens.

As empresas pesquisadas figuram na lista do ranking das "500 maiores e melhores empresas do Brasil" dos seguintes ramos de atuação: Comunicação Empresarial, Mercado de Capitais, Agronegócio e Alimentos, Engenharia e Construção Civil, Edição e Comunicação, Indústria de Aeronaves, Aviação Comercial, Papel e Celulose, Distribuição de Combustíveis, Cimento, Mineração e Siderurgia.

A pesquisa foi aplicada nas sedes destas instituições, em São Paulo - SP, em março de 2011. Cada entrevista durou aproximadamente 3 horas, considerando a visita nas instalações físicas internas e externas dos CDMs. Os encontros foram orientados pelo roteiro previamente elaborado, entretanto, com algumas questões de aprofundamento, como permite o método de entrevista semiestruturada. Esse formato colabora com a criação de um ambiente apropriado, em que os entrevistados têm a oportunidade de discorrer sobre seus pontos de vista. As entrevistas foram gravadas com a autorização dos participantes e posteriormente transcritas para análise, sendo assegurado o anonimato dos sujeitos da investigação.

\section{Apresentação dos resultados}

Os resultados referem-se à camada de definição da ontologia, ou seja, ao nível terminológico, em que um conjunto básico de conceitos e relações entre eles são descritos na ontologia. Os termos e suas relações foram obtidos após a análise de conteúdo das entrevistas, a partir de uma matriz de repostas construída com as informações colhidas de cada entrevistado. Foram selecionados os termos que mais se repetiram nas respostas. Outras fontes para a seleção dos termos foram os Guias de acervos dos CDMs pesquisados, além de informações contidas nos sites das empresas.

Uma grande parte do acervo é composta por peças de comunicação, materiais elaborados pela área de comunicação e marketing das empresas. Esses itens tem uma nomenclatura da área em que são 
produzidos, desconhecida pela equipe de profissionais responsáveis pelo registro desse material. A demora ou a não localização de itens são algumas das consequências da falta de alinhamento dos conceitos e da adequação da nomenclatura dos materiais.

O Quadro 1 apresenta uma parte da matriz de estruturação das respostas, modelo que foi replicado para cada tema abordado na pesquisa:

Quadro 1 - Matriz de resultados - Tipos documentais

\begin{tabular}{|c|c|c|c|c|c|c|c|c|c|c|c|}
\hline $\begin{array}{c}\text { Empresas } \\
\text { Pesquisadas / } \\
\text { Cobertura do } \\
\text { Acervo }\end{array}$ & 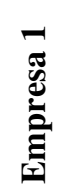 & 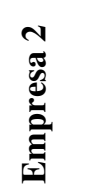 & 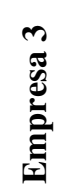 & 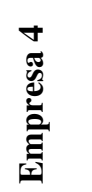 & 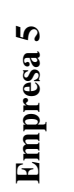 & 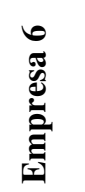 & 苞 & 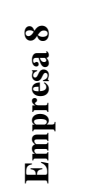 & 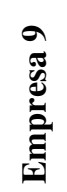 & 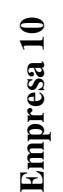 & 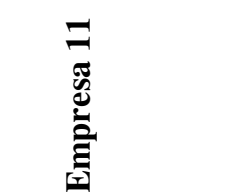 \\
\hline Audiovisual & 1 & 1 & 1 & 1 & - & 1 & 1 & 1 & 1 & 1 & 1 \\
\hline Cartográfico & 1 & 1 & 1 & - & - & - & 1 & 1 & 1 & 1 & 1 \\
\hline Eletrônico & 1 & 1 & 1 & - & - & 1 & 1 & 1 & 1 & 1 & 1 \\
\hline Iconográfico & 1 & 1 & 1 & - & 1 & 1 & 1 & 1 & 1 & 1 & 1 \\
\hline Textual & 1 & 1 & 1 & 1 & 1 & 1 & 1 & 1 & 1 & 1 & 1 \\
\hline Tridimensional & 1 & 1 & 1 & - & - & 1 & 1 & 1 & 1 & 1 & 1 \\
\hline Resultado & \multicolumn{2}{|c|}{ Audiovisual } & \multicolumn{2}{|c|}{ Cartográfico } & \multicolumn{2}{|c|}{ Eletrônico } & \multicolumn{2}{|c|}{ Iconográfico } & \multicolumn{2}{|c|}{ Textual } & Tridimensional \\
\hline & \multicolumn{2}{|c|}{10} & \multicolumn{2}{|c|}{7} & \multicolumn{2}{|c|}{9} & \multicolumn{2}{|c|}{10} & \multicolumn{2}{|c|}{11} & 9 \\
\hline
\end{tabular}

Fonte: Dados da pesquisa.

Nota: Audiovisual inclui itens sonoros de áudio e/ou vídeo. Cartográfico inclui mapas e desenhos. Eletrônico inclui documentos digitais. Iconográfico inclui documentos ilustrados ou imagens. Textual inclui documentos apenas com texto. Tridimensional inclui reália e outros objetos.

O Quadro 2 apresenta uma parte da matriz de estruturação das respostas para os assuntos cobertos pelo acervo: 
Quadro 2 - Matriz de resultados - classe assuntos do acervo

Empresas
Pesquisadas

\begin{tabular}{|c|c|}
\hline Empresa 1 & Foco preservação da Memória Institucional, Produtos e Pessoas \\
\hline Empresa 2 & Foco preservação da Memória Institucional, Produtos, Pessoas e Processos \\
\hline Empresa 3 & Foco divulgação da Memória Institucional e Produtos \\
\hline Empresa 4 & Foco difusão da Memória Institucional nas organizações \\
\hline Empresa 5 & Foco preservação da Memória de Produtos \\
\hline Empresa 6 & Foco preservação da Memória Institucional, Produtos e Pessoas \\
\hline Empresa 7 & Foco preservação da Memória Institucional, Produtos, Pessoas e Processos \\
\hline Empresa 8 & Foco preservação da Memória Institucional, Produtos, Pessoas e Processos \\
\hline Empresa 9 & $\begin{array}{c}\text { Foco preservação da Memória Institucional, por meio de Educação e ações escolares, Produtos, Pessoas e } \\
\text { Processos. Objetivo da divulgação para agregar clientes ao negócio. }\end{array}$ \\
\hline Empresa 10 & $\begin{array}{c}\text { Foco preservação da Memória Institucional, por meio de Educação e ações escolares, Produtos, Pessoas e } \\
\text { Processos. Objetivo da divulgação para agregar clientes ao negócio. }\end{array}$ \\
\hline Empresa 11 & $\begin{array}{c}\text { Foco preservação da Memória Institucional, por meio de Educação e ações escolares, Produtos, Pessoas e } \\
\text { Processos. Objetivo da divulgação para agregar clientes ao negócio. }\end{array}$ \\
\hline Resultado & $\begin{array}{lll}\text { Produtos } & \text { Pessoas } & \text { Processos }\end{array}$ \\
\hline & 10 \\
\hline
\end{tabular}

Fonte: Dados da pesquisa.

Os termos identificados referem-se ao tipo documental dos acervos, aos assuntos desses documentos, ao público-alvo e ao canal de disseminação dessas informações. Os documentos podem ser ainda considerados como itens individuais ou fazer parte de uma coleção, em que diversos itens são reunidos de acordo com a sua finalidade ou tema. Entretanto, por questões de delimitação, apenas serão tratados neste artigo os resultados referentes aos tipos dos documentos do CDM.

Em relação aos assuntos dos documentos, destaca-se que os mais citados nas entrevistas e que foram agrupados em 4 dimensões temáticas, estão todos presentes em pelo menos 60\% da amostra (se desconsiderada a dimensão processos, a menos citada, todas as outras três dimensões juntas estão presentes em $80 \%$ da amostra). As quatro dimensões temáticas identificadas são: 1) dimensão Institucional; 2) dimensão Produtos ou serviços; 3) dimensão Pessoas; e 4) dimensão Processos.

A pesquisa revela ainda que $73 \%$ da amostra (oito empresas) não têm esses mesmos assuntos descritos de forma padronizada para realizar a indexação dos documentos, apenas $27 \%$ (três empresas) usam pelo menos listas de vocabulário controlado. Com isso, nota-se que a amostra pesquisada armazena documentos praticamente dos mesmos assuntos, todavia, não os indexa de forma padronizada. Cada CDM atribui a um mesmo assunto nomenclaturas diferentes, de acordo com o ponto de vista do profissional que está indexando o documento, com base na linguagem natural. 
Nesse sentido, está a maior contribuição deste estudo: a partir das informações coletadas nos próprios CDMs, propor uma ontologia com cobertura dos termos para tipo documental, coleções, assuntos, públicoalvo e canal de disseminação, incluindo suas subclasses e instâncias, ontologia esta que posteriormente deve ser avaliada, validada ou estendida pela própria comunidade a que se destina.

A figura 1 representa a visão geral da ontologia, com os conceitos e as relações de um objeto CDM, em que esse é um item do acervo, que é também um tipo documental, que pode ou não compor uma coleção, que pode referir-se a mais de um assunto, porém, tem apenas um assunto principal, é destinado a um público-alvo e disponibilizado por um canal de atendimento.

Figura 1 - Conceitos e Relações Gerais - ObjetoCDM

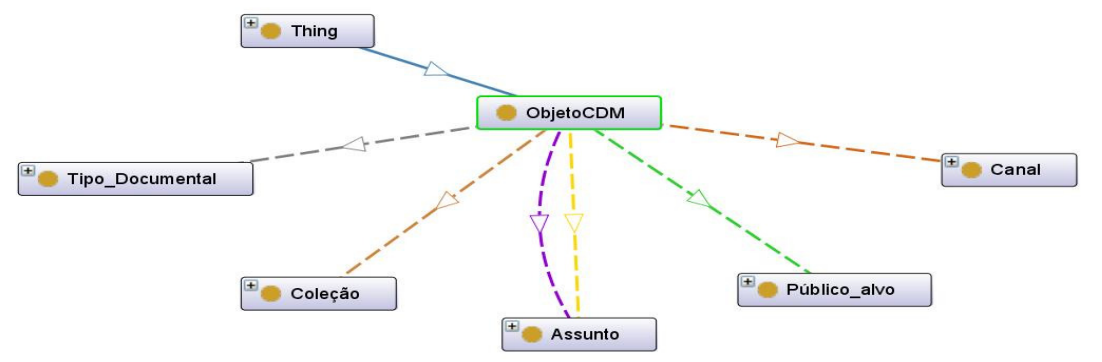

Fonte: Dados da pesquisa.

A figura 2 representa uma parte da proposta de ontologia, a dimensão tipo documental, com seu desdobramento em subclasses, subsubclasses e instâncias. Os termos desta dimensão, assim como todos os outros termos propostos na ontologia, foram construídos com base na análise de conteúdo das entrevistas realizadas e na análise de documentos, como manuais de procedimentos e guias de acervos dos CDMs, conteúdo dos sites disponíveis na Internet e outros documentos coletados durante as visitas.

Figura 2 - Subclasse e instâncias da Classe Tipo Documental Iconográfico

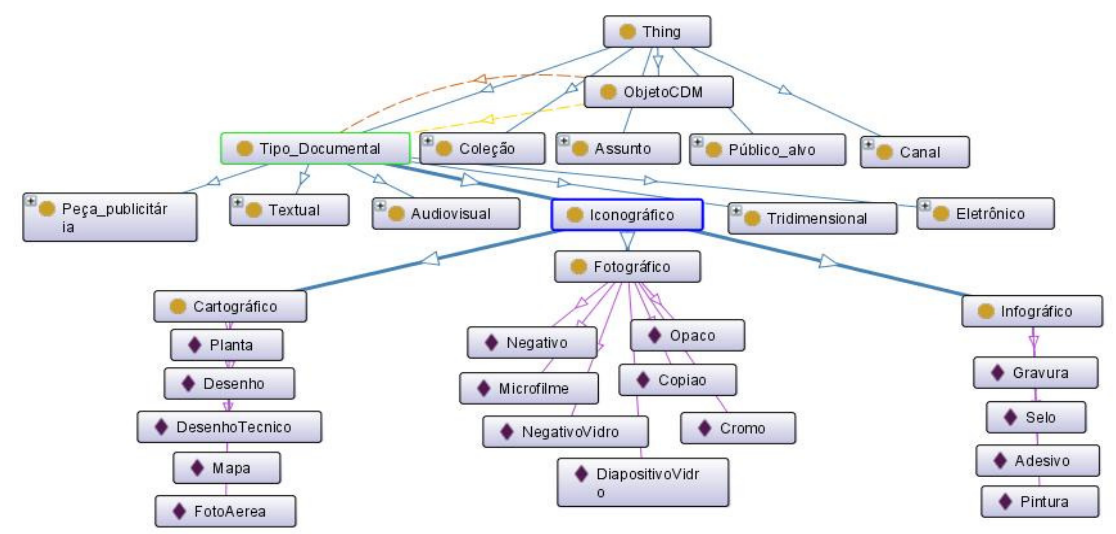

Fonte: Dados da pesquisa. 
O quadro 3 apresenta o detalhamento da classe Tipo Documental, subclasse Iconográfico, que abrange as subsubclasses: Cartográfico, Infográfico e Fotográfico. A subsubclasse Cartográfico apresenta as seguintes instâncias: Desenho, Desenho técnico, Foto aérea, Mapa e Planta. As instâncias da subsubclasse Infográfico são: Adesivo, Gravura, Pintura e Selo. As instâncias da subsubclasse Fotográfico: Copião, Cromo, Dispositivo Vidro, Microfilme, Negativo, Negativo de Vidro e Opaco.

Quadro 3 - Subclasses e instâncias da Classe Tipo Documental Iconográfico

\begin{tabular}{|c|c|c|c|}
\hline Classe & Subclasse & Sub-Subclasse & Instância \\
\hline Tipo Documental & Iconográfico & Infográfico & $\begin{array}{c}\text { Desenho } \\
\text { Desenho técnico } \\
\text { Foto aérea } \\
\text { Mapa } \\
\text { Planta } \\
\text { Adesivo } \\
\text { Gravura } \\
\text { Pintura } \\
\text { Selo } \\
\text { Copião } \\
\text { Cromo } \\
\text { Dispositivo Vidro } \\
\text { Microfilme } \\
\text { Negativo } \\
\text { Negativo de Vidro } \\
\text { Opaco }\end{array}$ \\
\hline
\end{tabular}

Fonte: ESTEVÃO (2012).

Essa proposta procurou abordar os tópicos mais representativos em relação aos tipos documentais identificados como mais citados nas entrevistas nos CDMs pesquisados. Há, ainda, outros aspectos dos documentos de um CDM, como, por exemplo: assuntos, coleção, públicoalvo e canal de disseminação que, nesse momento, não foram contemplados neste artigo, mas estão descritos em Estevão (2012)

\section{Considerações finais}

Concluiu-se, ao longo da pesquisa, que as iniciativas de $\mathrm{MOH}$ servem, de fato, como canais disseminadores do conhecimento histórico organizacional e ferramentas de uso estratégico para a Instituição, não se limitando como guardiãs de registros internos. Ainda que muitas organizações apenas registrem os momentos mais marcantes em forma de livros lançados em datas comemorativas, como os aniversários da empresa, por exemplo. Outras estruturaram CDMs para que a preservação de informações não apenas "celebrativa", mas informações que possam ter um uso estratégico pudessem ser armazenadas, recuperadas e reutilizadas em toda a organização, entretanto de forma não otimizada.

Essas informações referem-se aos assuntos cobertos pelo conteúdo informacional de um CDM, que traduz a cultura, a identidade, a retórica institucional e a reputação percebida de uma marca, tendo todo o 
potencial para serem usados a favor dos objetivos presentes e do futuro da organização.

Nesse sentido, a ontologia é uma estrutura capaz de representar os conteúdos dos repositórios no domínio da memória organizacional histórica, promovendo, assim, a busca e a recuperação da informação. Os conceitos estarão previamente definidos, tendo as relações com outros conceitos do domínio estabelecidas e as restrições declaradas. Assim, a ontologia permite a padronização dos conceitos usados para indexar os assuntos, ou seja, qualquer colaborador efetivo ou terceiro, que trabalhe com a indexação dos itens do acervo, terá disponível esse modelo conceitual permitindo que ele tenha a compreensão e faça uso dos mesmos conceitos.

A proposta de uma ontologia como modelo de referência de um domínio permite que, a partir da criação de um modelo conceitual explícito da base de conhecimento desse domínio, se tenha subsídios para o desenvolvimento de ferramentas de busca e recuperação da informação baseadas em contexto, que garantam a precisão e a velocidade da recuperação de informações, o suporte a tomada de decisões, a alta revocação com precisão (maior parte das respostas utilizáveis), gerando confiabilidade e credibilidade à base de dados corporativos. A habilidade desta ferramenta de busca em atuar apoiada em uma estrutura conceitual, baseada em descrições ontológicas e relações semânticas, servirá como instrumento de categorização e classificação do conhecimento organizacional histórico, usando como critérios de busca os conceitos e suas inferências, não apenas a repetição de palavras sem contexto, o que melhora significativamente o seu desempenho.

\section{Referências}

ALMEIDA, M. B. Um modelo baseado em ontologias para representação da memória organizacional. 345f. 2006. Tese (Doutorado em Ciência da Informação) - Curso do Programa de Pós Graduação da Escola de Ciência da Informação da Universidade Federal de Minas Gerais, Belo Horizonte, 2006.

ASSOCIAÇÃO BRASILEIRA DE COMUNICAÇÃO EMPRESARIAL. Aberje comemora o Dia da Memória Organizacional. Notícias Aberje, 8 ago. 2008. Disponível em: <http://www.aberje.com.br/acervo_not_ver.asp?ID_

NOTICIA=180\&EDITORIA=Geral $>$. Acesso em: 11 out. 2010.

BARDIN, L. Análise de conteúdo. Lisboa: Gráfica Telles da Silva, c1977.

BERNERS-LEE, T.; HENDLER, J.; LASSILA, O. The semantic web. Scientific American, United States, v. 284, n. 5, p. 34-43, Maio 2001.

BOCCATO, V. R. C.; RAMALHO, R. A. S.; FUJITA, M. S. L. A contribuição dos tesauros na construção de ontologias como instrumento de organização e recuperação da informação. IBERSID: Revista de Sistemas de Información y Documentación, número monográfico, p. 199-209, 2008. 
BROOKING, A. Corporate memory: strategies for knowledge management. London: International Thomas Business Press, 1999.

CAMPOS, M. L. de A. Modelização de domínios do conhecimento: uma investigação de princípios fundamentais. Ciência da Informação, Brasília, v. 33, n. 1 , p. 22-32, jan./abr. 2004. Disponível em: <http://www.scielo.br/pdf/ci/v33n1/v33n1a03.pdf>. Acesso em: 13 mar. 2011.

CHOO, C. W. A organização do conhecimento: como as organizações usam a informação para criar significado, construir conhecimento e tomar decisões. São Paulo: SENAC São Paulo, 2003.

DAHLBERG, I. Teoria do conceito. Ciência da Informação, Rio de Janeiro, v. 7, n. 2, p. 101-107, jul./dez. 1978. Disponível em: <http://revista.ibict.br/index.php/ciinf/article/view/1680/1286>.

Acesso em: 2 abr. 2011.

DAMANTE, N. Conhece-te a ti mesmo: entender a história como elemento de responsabilidade social conduz empresas e organizações à autoanálise. Revista Comunicação Empresarial, São Paulo, v. 14, n. 52, p. 2835, 2004.

ESTEVÃO, J. S. B.; STRAUHS, F. do R. Proposta de um modelo de referência flexível de ontologia no domínio da Memória Organizacional Histórica. In: CONGRESO LATINO-IBEROAMERICANO DE GESTIÓN TECNOLÓgICA (ALTEC), 14. 2011, Lima - Peru. Anais... Lima: ALTEC, 2011.

ESTEVÃO, J. S. B.. Proposta de uma ontologia como modelo de referência no domínio da Memória Organizacional Histórica. 2012. 157f. Dissertação (Mestrado em Tecnologia) - Programa de Pós-graduação em Tecnologia, Universidade Tecnológica Federal do Paraná, Curitiba, 2012.

GOMES, H. E. Manual de elaboração de tesauros monolíngues. Brasília: Programa Nacional de Bibliotecas das Instituições de Ensino Superior, 1990.

GUARINO, N. Understanding, building, and using ontologies. International Journal of Human-Computer Studies, London, v. 46, n. 2-3, p. 293-310, fev./mar. 1997.

GUARINO, N. Formal Ontology in Information Systems. In: INTERNATIONAL CONFERENCE ON FORMAL ONTOLOGY IN INFORMATION SYSTEMS (FOIS'98), 1., 1998, Trento, Italy. Proceedings... Amsterdam: IOS Press, 1998. p. 3-15.

INSTITUTO BRASILEIRO DE INFORMAÇÃO EM CIÊNCIA E TECNOLOGIA (IBICT). Diretrizes para elaboração de tesauros monolíngües. Brasília: IBICT, 1984.

JASPER, R.; USCHOLD, M. A framework for understanding and classifying ontology Applications. 1999. Disponível em: 
<http://folk.ntnu.no/alexanno/skole/WebInt/Articles/Articles.pdf > Acesso em: 20 jul. 2011.

LIBRARY OF CONGRESS. What is a Marc Record, and why is it Important? 2009. Disponível em: < http://www.loc.gov/marc/umb/um01to06.html>. Acesso em: 9 abr. 2011.

MCGUINNESS, D. Ontological issues for knowledge: enhanced search. In: INTERNATIONAL CONFERENCE FORMAL ONTOLOGY IN INFORMATION SYSTEMS - FOIS'98, 1., 6-8 jun. 1998, Trento, Italy. Proceedings... Amsterdam: IOS Press, 1998. p. 302-316.

MUSEU DA PESSOA. Workshop celebrações: como utilizar a memória da sua empresa em grandes eventos comemorativos. São Paulo: Museu da Pessoa, 2005.

NASCIMENTO, M. S. O. do et al. A ontologia na ciência da informação. Revista Digital de Biblioteconomia e Ciência da Informação, Belo Horizonte, v. 5, n. 1, p. 13-39, jul./dez. 2007.

NASSAR, P. Questões de memória. One Voice, 1 jun. 2009. Entrevista concedida à Camila Amorin.

NONAKA, I.; TAKEUCHI, H. Criação de conhecimento na empresa: como as empresas japonesas geram a dinâmica da inovação. Rio de Janeiro: Campus, 1997.

NONAKA, I.; TAKEUCHI, H. Criação de conhecimento na empresa: como as empresas japonesas geram a dinâmica da inovação. Rio de Janeiro: Campus, 1997.

ONLINE COMPUTER LIBRARY CENTER (OCLC). WorldCat facts and statistics. 2011. Disponível em: <http://www.oclc.org/us/en/worldcat/statistics/default.htm>. Acesso em: 9 abr. 2011.

REMOR, L. de C.; RADOS, G. V.; REMOR, C. A. M. A construção da memória organizacional utilizando o gerenciamento de processo nas pactuações da comissão intergestores bipartite do sistema único de saúde. Enc. Bibli: Revista Eletrônica Biblioteconomia e Ciência da Informação, Florianópolis, v. 14, n. 27, p.85-97, 2009.

SALES, L. F. Ontologias de domínio: estudo das relações conceituais e sua aplicação. 2006. Dissertação (Mestrado em Ciência da Informação) Instituto Brasileiro de Informação em Ciência e Tecnologia. Universidade Federal Fluminense, Niterói, 2006. Disponível em: <http://www.enancib.ppgci.ufba.br/premio/UFF-IBICT_Sales.pdf>. Acesso em: 7 set. 2010 .

SALES, L. F.; CAMPOS, M. L. de A.; GOMES, H. E. Ontologias de domínio: estudo das relações conceituais. Perspectivas em Ciência da Informação, v. 13, n. 2, p. 62-76, maio/ago. 2008. Disponível em: <http://www.scielo.br/scielo.php?pid=S1413-

99362008000200006\&script $=$ sci_arttext $>$. Acesso em: 7 set. 2010. 
SOWA, J. F. Knowledge representation: logical, philosophical, and computational foundations. California: Brooks Cole; Pacific Grove, 2000.

SPILLER, A. R. Memória organizacional e reutilização do conhecimento técnico: estudo de caso em uma indústria multinacional eletroeletrônica no Brasil. 2005. 172f. Dissertação (Mestrado em Administração de Empresas) - Centro Universitário Álvares Penteado - Fecap, São Paulo, 2005. Disponível em: <http://200.169.97.105/biblioteca/imagens/000004/00000478.pdf > Acesso em: 19 nov. 2009.

TONINI, B.; GAGETE, É. Memória empresarial: uma análise da sua evolução. In: MEMÓRIA de Empresa: história e comunicação de mãos dadas, a construir o futuro das organizações. São Paulo: Aberje, 2004a. p. 113- 126.

TONINI, B.; GAGETE, É. Como transformar a memória empresarial em ferramenta de gestão. São Paulo: Aberje, 2004b.

USCHOLD, M. Building ontologies: towards a unified methodology. In: ANNUAL CONF. OF THE BRITISH COMPUTER SOCIETY SPECIALIST GROUP ON EXPERT SYSTEMS, 16., Cambridge, UK, 1996. Proceedings... Cambridge, 1996. Disponível em: <http://www.imamu.edu.sa/Scientific_selections/abstracts/Abstract\%20 $\% 20 I T \% 20 \% 203 / B u i l d i n g \% 200$ ntologies $\% 20 T o w a r d s \% 20 a \% 20 U n i t e d \% 2$ OMethodology.pdf>. Acesso em: 20 mar. 2011.

WALSH, J. P.; UNGSON, G. R. Organizational memory. The Academy of Management Review, United States, v. 16, n. 1, p. 57-91, 1991.

WELTY, C. A. the ontological nature of subject taxonomies. In: INTERNATIONAL CONFERENCE FORMAL ONTOLOGY IN INFORMATION SYSTEMS - FOIS'98, 1., 6-8 jun. 1998, Trento, Italy. Proceedings... Amsterdam: IOS Press, $1998 . \quad$ Disponível em: <http://www.cs.vassar.edu/ weltyc/papers/fois-98/fois-98-1.html>. Acesso em: 15 nov. 2011.

WORCMAN, K. Memória do futuro: um desafio. In: MEMÓRIA de Empresa: história e comunicação de mãos dadas, a construir o futuro das organizações. São Paulo: Aberje, 2004.

WORLD WIDE WEB CONSORTIUM (W3C). Facts About W3C. $2011 \mathrm{a}$. Disponível em: <http://www.w3.org/Consortium/facts>. Acesso em: 1 maio 2011.

WORLD WIDE WEB CONSORTIUM (W3C). About W3C. 2011b. Disponível em: <http://www.w3.org/Consortium>. Acesso em: 1 maio 2011 